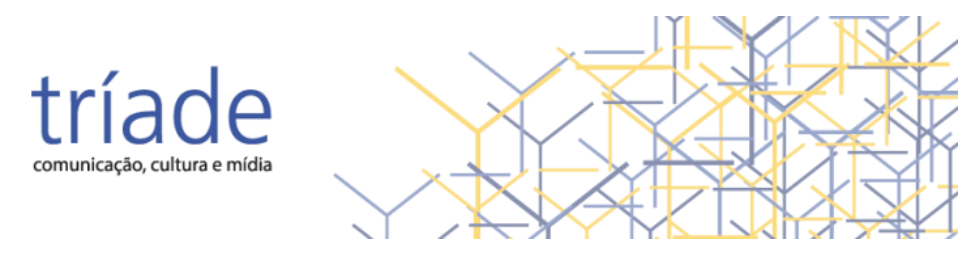

\title{
O uso do WhatsApp nas eleições de 2018 e as lacunas teóricas da Justiça Eleitoral
}

The WhatsApp use in the 2018 elections and the theoretical gaps in the Electoral Justiçe

El uso del WhatsApp em las elecciones de 2018 y las brechas teóricas em la justicia electoral

Isabella Alonso Panho - Universidade Estadual de Londrina | Londrina | São Paulo | Brasil | isabella.alonso17@gmail.com | (D) https://orcid.org/0000-0002-8350-5412.

Manoel Dourado Bastos - Universidade Estadual de Londrina | Londrina | São Paulo | Brasil I manoel.bastos@gmail.com I (D) https://orcid.org/0000-0001-5874-2400.

Gabriela Fernandes Silva - Universidade Estadual de Londrina | Londrina | São Paulo | Brasil | gabi_fs@hotmail.com.br | (D) https://orcid.org/0000-0003-1687-3650.

Resumo: O uso dos disparos massivos de mensagens pelo WhatsaApp nas últimas eleições presidenciais passou a ser objeto de olhares mais críticos a partir de uma reportagem publicada na Folha de S. Paulo, em outubro de 2018. Com as denúncias veiculadas, várias ações judiciais foram protocolizadas junto ao TSE (Tribunal Superior Eleitoral), que firmou, na época, o entendimento de que se tratava de comunicação espontânea do eleitorado - o que inviabilizou, naquele momento, o aprofundamento das investigações. Partindo desse objeto, a proposta deste artigo é desconstituir tanto as posições adotadas pelo TSE como o respaldo legal que as embasa por meio dos conceitos da (Crítica da) Economia Política da Comunicação, caracterizando a circulação de mercadoria-audiência nos fenômenos compreendidos como comunicação orgânica. Para tal análise, parte-se do aparato teórico tecido por Bolaño e por Smythe, que analisam a forma social comunicação dentro das novas configurações assumidas pelo capital.

Palavras-chave: WhatsApp. Eleições de 2018. Justiça Eleitoral.

Abstract: The massive use of WhatsaApp messages in the last presidential elections has come under more critical scrutiny after a report published in Folha de S. Paulo in October 2018. With the published revelations, several lawsuits begun in the SEC (Superior Electoral Court), which established, at the time, the understanding that it was spontaneous communication by the electorate - what made impossible, in that moment, deepen the investigations. Based on this object, the purpose of this article is to deconstruct the positions adopted by the TSE and its legal support through the lens of the concepts of (Critique of) Political Economy of Communication, showing the circulation of audience- 


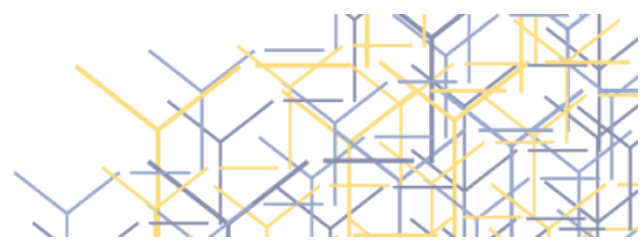

merchandise in the episodes understood as organical comunication. For such an analysis, we start from the theoretical apparatus woven by Bolaño and Smythe, who analyze the social form communication within the new configurations assumed by capital.

Keywords: Whatsapp. 2018 election. Electoral justice.

Resumen: El disparo masivo de mensajes por WhatsaApp en las últimas elecciones presidenciales ha sido objeto de un examen más crítico después de un informe publicado en Folha de S. Paulo en octubre de 2018. Con las revelaciones publicadas, se presentaron varias demandas juntas al TSE (Tribunal Superior Electoral), que estableció, en aquel momento, el entendimiento de que era una comunicación espontánea por parte del electorado, lo que hizo imposible profundizar las investigaciones. En base a este objeto, el propósito de este artículo es desmantelar tanto las posiciones adoptadas por el TSE como el apoyo legal que las respalda atraves de los conceptos de (Crítica de) Economía Política de la Comunicación, que caracteriza la circulación de la mercancia-audiencia en los fenómenos entendidos como comunicación orgánica. Para tal análisis, partimos del aparato teórico tejido por Bolaño y Smythe, quienes analizan la forma social comunicación dentro de las nuevas configuraciones asumidas por el capital.

Palabras clave: Whatsapp. Elecciones de 2018. Justifica electoral. 


\section{Introdução}

No dia 18 de outubro de 2018, dez dias antes do segundo turno das eleições que levariam o candidato Jair Bolsonaro, do PSL (Partido Social Liberal), à presidência da República, uma reportagem de Patrícia Campos Mello (2018) publicada na Folha de S. Paulo denunciava que diversas empresas teriam comprado pacotes de disparos de mensagens em massa pelo WhatsApp contra o PT (Partido dos Trabalhadores), numa dupla violação das leis eleitorais. Diante do cenário de crise institucional criado pelas denúncias, a ministra Rosa Weber, presidente do TSE (Tribunal Superior Eleitoral), decidiu dar uma entrevista coletiva, ocorrida faltando apenas uma semana para a eleição. Reunindo diversas autoridades, a expectativa era apaziguar a desconfiança que pairava sobre as eleições. Após as falas das autoridades, a coletiva foi finalmente aberta para as perguntas dos repórteres. Um deles questionou se a ministra acreditava que o TSE havia perdido a luta contra a desinformação. A pergunta era bastante incisiva, tendo em vista que o Tribunal havia escolhido o tema das fake news como a questão central nas eleições de $2018^{1}$. A resposta de Weber foi emblemática e aponta para as dificuldades da Justiça Eleitoral em lidar com a questão. "Gostaríamos imenso de ter uma solução pronta e eficaz. De fato, não temos" (FABRINI, 2018).

O tema da desinformação tem se apresentado como um assunto cada vez mais relevante nos estudos de comunicação e política. Tema recorrente em estudos clássicos do campo, mesmo que na maior parte das vezes em negativo, sua proeminência se deu com o avanço das TIC's (Tecnologias da Informação e Comunicação), entendidas como principal vetor da presença inapelável das fake news no cenário político como um todo, particularmente na dinâmica eleitoral.

\footnotetext{
${ }^{1}$ Foi firmado, em junho de 2018, um termo de compromisso que continha um acordo de colaboração entre TSE e os partidos políticos para o combate à disseminação de notícias falsas durante o período eleitoral (TSE, 2018a).
} 
O crescimento da população que dispõe de acesso à rede mundial de computadores, por meio dos celulares e seus aplicativos, fundamentalmente, as chamadas mídias sociais, é visto como um dos elementos decisivos da consolidação da desinformação como fator central da dinâmica eleitoral, conjugação que se apresenta como um foco de estudos cada vez mais privilegiado no campo da comunicação e política. Especialmente no caso das dinâmicas eleitorais (por exemplo, uma pesquisa rápida no Google Acadêmico com os indexadores "Bolsonaro" e "WhatsApp" devolveu mais de 1,5 mil resultados no momento do fechamento deste artigo), as diversas áreas do conhecimento interessadas na correlação entre comunicação e política têm procurado desenvolver estudos científicos sobre a questão da desinformação. Ou seja, se não há "uma solução pronta e eficaz", como assombrosamente afirmou a ministra Rosa Weber, há um conjunto significativo de produção científica que encaminha recursos analíticos capazes de colaborar com a gestão de processos eleitorais.

Tendo isso em vista, o presente trabalho busca estabelecer uma análise da concepção incorporada pela Justiça Eleitoral no que diz respeito ao uso de aparatos midiáticos para a disseminação de desinformação em meio a processos eleitorais. Focaremos particularmente as peças jurídicas referentes às denúncias de disparo de mensagens em massa no WhatsApp contra o PT nas eleições presidenciais de 2018, que recaíram como diferentes acusações contra a chapa do então candidato Jair Bolsonaro. Visaremos justamente compreender as lacunas sobre Comunicação que sobressaem no discurso jurídico materializado nas peças dos diferentes processos. O principal foco de análise se encontra no entendimento adotado pelo TSE para analisar as denúncias de que fundamentalmente se trata de comunicação espontânea do eleitorado. Este foco se apresenta como relevante visto que, após uma consulta aos principais artigos já desenvolvidos sobre o tema, nenhum deles deu especial atenção às peças 


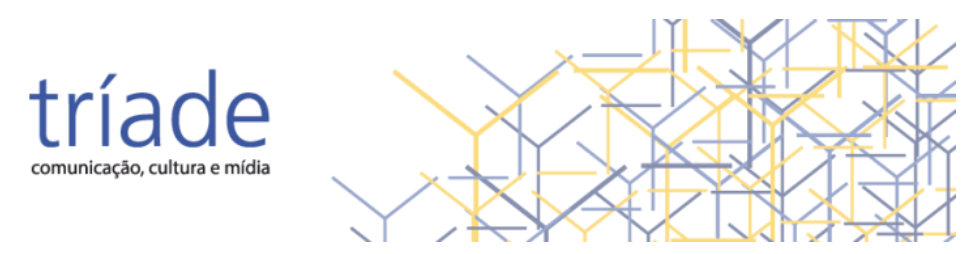

jurídicas, muito menos ao tema especificamente proposto².

Para isso, ao longo do desenvolvimento do texto vamos tratar a questão do seguinte modo. Inicialmente, dedicaremos atenção à legislação brasileira pertinente ao tema. Em seguida, focaremos nas peças jurídicas relativas ao objeto de estudo. A partir disso, veremos especialmente uma lacuna teórica significativa no discurso jurídico sobre a comunicação espontânea do eleitorado, o que mostra certa fragilidade da legislação e, consequentemente, das decisões nos casos específicos, a saber: a inexistência de uma compreensão de como funciona a produção da audiência como mercadoria. Para apontar essa lacuna, recorreremos aos marcos da Economia Política da Comunicação, fundamentalmente segundo a obra de César Bolaño (2000). Trata-se de argumento coeso para uma avaliação das articulações entre comunicação e política, principalmente no que diz respeito ao caráter da produção de audiências. Ao fim, faremos a exposição das considerações finais, apontando para a importância de um conhecimento adequado das Teorias da Comunicação pela Justiça Eleitoral brasileira, o que significa dizer que os estudos das relações entre comunicação e política devem ser reconhecidos como peças centrais para esta instituição decisiva nas campanhas eleitorais em particular e na democracia como um todo.

\footnotetext{
2 Para efeito de análise, fizemos uma consulta no Google Acadêmico e reconhecemos os temas compartilhados pelos artigos mais relevantes (segundo a métrica do buscador), a saber: Fake News e Desinformação; Ataque à Democracia; Conteúdos das mensagens e estratégias discursivas; Perfil de usuários disseminadores de conteúdo; Campanha eleitoral online (relação entre WhatsApp e Campanha; Relação entre Trump e Bolsonaro; Dados, algoritmos e automação; Apoiadores e presença partidária nas redes sociais digitais; Disseminação; Outros (ou seja, aqueles que só se encontram em apenas um artigo: Reação do Jornalismo às Fake News; Mobilização do meme "O Brasil vai virar uma Venezuela"; Possibilidades de rastreio de fontes originais das notícias; Sistema para visualizar grupos no WhatsApp). Nenhum deles trata diretamente do discurso jurídico sobre a desinformação, mais ainda sobre a questão da comunicação espontânea do eleitorado, o que justifica um estudo como o apresentado aqui. Por sua vez, todos eles foram muito importantes para reconhecermos que há um conjunto relativamente sólido de produção teórica sobre o tema, mas aparentemente ignorado pela Justiça Eleitoral, como demonstraremos a seguir.
} 


\section{Desenvolvimento}

O Código Eleitoral (Lei n. 4.737/1965) (BRASIL, 1965) fixa normas gerais do funcionamento das eleições e da Justiça Eleitoral - tanto em termos de estrutura administrativa quanto de sistema processual - a passo que a Lei de Eleições (Lei n. 9.504/1997) (BRASIL, 1997) trata de elementos mais específicos sobre a campanha, seu funcionamento, proibições e permissões - sendo esta última o fundamento de estudo relevante para as questões suscitadas neste artigo.

Além de tais dispositivos - que são normas chanceladas pelo Poder Legislativo - ainda há a Resolução do TSE n. 23.551, de 18 de dezembro de 2017 (TSE, 2018b), que estabelece ainda mais detalhes sobre o funcionamento da campanha eleitoral, detalhando o que estabelece a Lei de Eleições.

A inclusão dos meios virtuais de realização de campanha foi progressivamente realizada a partir de diversas alterações feitas nas normas destacadas. Como exemplo disso, até as eleições proporcionais de 2016 era vedada qualquer forma paga de campanha na internet. Contudo, antes das majoritárias de 2018, precisamente no dia 7 de outubro de 2017, foi promulgada a Lei n. 13.488 (BRASIL, 2017), que alterou a Lei de Eleições, regulando a propaganda por meios virtuais.

Essa reforma tem dois pontos mais relevantes: a possibilidade de impulsionamento de materiais de campanha e a inclusão de um capítulo inteiro sobre a propaganda através de internet.

A Resolução n. 23.551/17 do TSE define o impulsionamento como todo "mecanismo ou serviço que, mediante contratação com os provedores de aplicação de internet, potencializem o alcance e a divulgação da informação para atingir usuários que, normalmente, não teriam acesso ao seu conteúdo" (TSE, 2018a). Em outras palavras, é todo e qualquer investimento pecuniário que privilegie a circulação de determinado conteúdo na plataforma ou rede social em que ele está inserido, fazendo 
com que ele atinja um maior número de pessoas ou apareça com mais frequência para os usuários.

A permissão de impulsionamento, contudo, deve obedecer a determinadas balizas. Os gastos empreendidos com tal forma de propaganda eleitoral devem ser incluídos na prestação de contas de campanha, se sujeitando a todas as normas e limites previstos para os demais veículos (como o rádio e a televisão). É o que estabelece art. 26, parágrafo segundo, da Lei de Eleições: "§ 20 Para os fins desta Lei, incluise entre as formas de impulsionamento de conteúdo a priorização paga de conteúdos resultantes de aplicações de busca na internet (BRASIL, 1997)".

A partir disso, a lei brasileira deixou de fazer distinção entre o que é gasto com um anúncio de televisão, por exemplo, e o impulsionamento de uma publicação em uma rede social. Ambos os gastos devem ser contabilizados nos balanços das campanhas.

Por sua vez, no capítulo destinado exclusivamente à propaganda eleitoral pela internet (artigos 57-A a 57-J), logo nos primeiros artigos, já fica determinado que a propaganda feita pela internet deve-se dar em antros específicos: o endereço eletrônico (site) ou redes sociais próprias do candidato, do partido ou da coligação a que pertence.

A veiculação de mensagens é permitida apenas em listas cuja inscrição seja voluntária e que permitam o cancelamento do serviço por parte do eleitor.

Ainda, as mensagens distribuídas por meios eletrônicos não podem ser enviadas ou confeccionadas por qualquer tipo de entidade. De acordo com a lei, apenas o próprio candidato, partido ou coligação e eleitores comuns podem ser produtores de tais conteúdos - com a ressalva de que as pessoas físicas não podem impulsioná-los. Ou seja, não pode haver qualquer investimento para potencializar a circulação de conteúdo similar ao de propaganda eleitoral quando ele for transmitido por pessoas comuns.

Essas regras constam nos artigos 57-B e 57-C da Lei de Eleições (BRASIL, 1997). Nesses mesmos dispositivos, está vedado às pessoas 


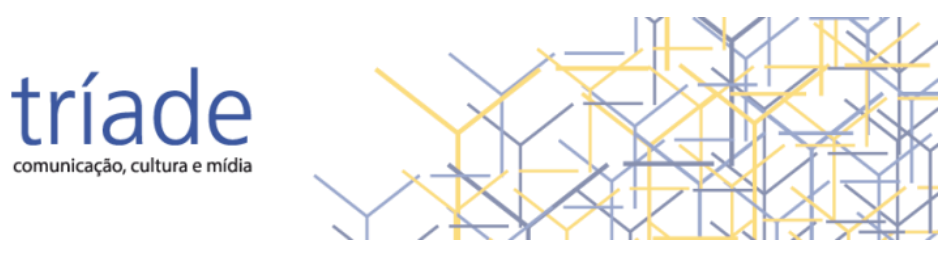

físicas que ajam de forma anônima. Assim, além de não poderem veicular conteúdos impulsionados, devem fazê-lo sempre de forma identificada, sob pena de a conduta configurar crime eleitoral, passível de penalizar o candidato.

As disposições da lei eleitoral são, nas situações demonstradas neste trabalho, taxativas e não exemplificativas. Com isso, sua interpretação deve se dar de forma restritiva e literal: apenas o que está escrito na lei é permitido e pode ser feito, vedando-se uma interpretação extensiva e ampla que the flexibilize seu sentido.

A vedação do anonimato ainda é reforçada no artigo 57-D da Lei de Eleições e pela Resolução n. 23.551/17, que dedica uma seção inteira aos requisitos necessários para a requisição judicial de informações sobre os usuários.

Segundo se faz constar nos artigos 34 e 35 dessa Resolução ${ }^{3}$ (TSE, 2018a), os provedores de plataformas das redes sociais só podem ser obrigados por força de ordem judicial a fornecer dados sobre os agentes disparadores de mensagens. Ainda, para que esse tipo de decisão seja dada pelo Judiciário, deve haver um pedido que demonstre ou a existência indícios concretos de que há algum ilícito ou a utilidade desses dados para

\footnotetext{
${ }^{3}$ Art. 34. O provedor responsável pela guarda somente será obrigado a disponibilizar os registros de acesso a aplicações de internet, de forma autônoma ou associados a dados cadastrais, dados pessoais ou a outras informações disponíveis que possam contribuir para a identificação do usuário, mediante ordem judicial, na forma prevista nesta Seção.

Art. 35. O representante poderá, com o propósito de formar conjunto probatório, em caráter incidental ou autônomo, requerer ao juiz eleitoral que ordene ao responsável pela guarda o fornecimento dos dados constantes do art. 33.

$\S 1^{\circ}$ Sem prejuízo dos demais requisitos legais, o requerimento deverá conter, sob pena de inadmissibilidade:

I - fundados indícios da ocorrência do ilícito de natureza eleitoral;

II - justificativa motivada da utilidade dos dados solicitados para fins de investigação ou instrução probatória;

III - período ao qual se referem os registros.

$\S 2^{\circ} \mathrm{A}$ ausência de identificação imediata do usuário responsável pela divulgação do conteúdo não constitui circunstância suficiente para o deferimento do pedido de quebra de sigilo de dados.

$\S 3^{\circ} \mathrm{A}$ ordem judicial que apreciar o pedido deverá conter, sob pena de nulidade, fundamentação específica quanto ao preenchimento de todos os requisitos legais previstos nos incisos I a III do $\S 1^{\circ}$.
} 
fundamentar alguma investigação. Apesar de ser proibido pela lei eleitoral, o anonimato, sozinho, não é suficiente para a quebra desse sigilo da atividade das plataformas.

Conclui-se, deste modo, que pessoas físicas que desejem veicular material de campanha necessitam sempre se identificar, devendo tal ato ser livre de qualquer forma de subsídio econômico, seja no momento da produção, seja no momento de circulação. O fito de tal norma é proteger a livre manifestação do indivíduo, afastando, contudo, sua instrumentalização por entes empresariais privados. A penalidade imposta, na hipótese de infração dos dispositivos legais mencionados, é sempre de multa pecuniária, cujos valores transitam entre cinco e cinquenta mil reais. A Justiça Eleitoral, se reconhecer a prática de tais infrações, é quem determinará o valor exato da multa.

Tecidas tais considerações, indo em direção ao objeto específico deste artigo, é oportuno analisar os posicionamentos adotados pelo TSE em alguns processos nos quais houve questionamento dos métodos de campanha de Jair Messias Bolsonaro (Coligação Brasil acima de tudo, Deus acima de todos) na campanha majoritária de 2018, que o levou à cadeira da presidência.

Para se delimitar o objeto pesquisado, o método de busca escolhido consista na seleção de julgados junto ao site do TSE, através da busca, na aba de "Jurisprudência", das palavras-chave "Bolsonaro" e "whatsapp". Estão disponíveis para consulta 27 acórdãos ${ }^{4}$, cuja discussão se comunica com o uso de redes sociais na campanha, publicados desde o dia de veiculação da matéria pela Folha de $\mathrm{S}$. Paulo apontando irregularidades na (U) campanha (em 18/10/2018) até a conclusão deste trabalho. Muitos processos ainda estão em trâmite, inexistindo decisão definitiva e estável.

\footnotetext{
${ }^{4}$ Os acórdãos são decisões finais do tribunal, a passo que as decisões monocráticas são apenas do relator, podendo ser alteradas até o final do processo.
} 
Alguns desses também não têm propriamente a ver com o candidato eleito - sendo as palavras-chave mencionadas como mera referência.

Esses 27 acórdãos pertencem a 20 processos judiciais. Desses, três são Ações de Investigação Judicial Eleitoral, modalidade processual cujo objetivo é solicitar a investigação de atos ilícitos de campanha, seguindo um rito de processo de conhecimento ${ }^{5}$. A de mais relevância para este estudo é a AIJE (Ação de Investigação Judicial Eleitoral) n. 060177128.2018.6.00.0000 (BRASIL, 2018a), cujo autor é a Coligação "O Povo Feliz de Novo" (PT/PCdoB/PROS). Ela foi protocolada logo após a publicação da matéria da Folha de S. Paulo e teve como pedido final a inelegibilidade da chapa "Brasil acima de tudo, Deus acima de todos".

São réus desta ação o presidenciável Jair Messias Bolsonaro e seu vice, Antonio Hamilton Mourão - quem seriam os beneficiários diretos dos disparos denunciados pela Folha de S. Paulo - e também Luciano Hang, Quick Mobile Desenvolvimento e Serviços Ltda, Yacows Desenvolvimento de Sotware Ltda, Croc Services Soluções de Informática Ltda, SMS Market Soluções Inteligentes Ltda e, por fim, contra o próprio Whatsapp. Posteriormente, os indivíduos registrados ante as Juntas Comerciais Estaduais como sócios foram também incluídos como réus-investigados.

Até a conclusão deste trabalho, ainda não havia decisão final no processo. Apesar de ele estar indo em direção ao seu desfecho - com a apresentação de alegações finais pelas partes - foi determinada a reabertura da fase de produção de provas em virtude de uma manifestação do Whatsapp na AIJE de n. 0601782-57.2018.6.00.0000 (BRASIL, 2018a), cuja autora é a Coligação Brasil Soberano, formada pelo PDT e pelo Avante.

<U Nessa petição, datada de novembro de 2019, o Whatsapp reconheceu algumas práticas cuja investigação foi solicitada, de autoria das empresas Yacows, SMSMarket, Quick Mobile Desenvolvimento e Serviços Ltda. e Croc

\footnotetext{
${ }^{5} \mathrm{O}$ processo de conhecimento é um tipo de rito processual que permite a produção de provas, tais como ouvir testemunhas, requisitar documentos sigilosos, fazer perícias.
} 
Services Soluções de Informática Ltda, informando que teria as notificado a cessar tais violações em 48h (BRASIL, 2018b).

A partir disso, as três AIJEs que ainda tramitam no TSE passaram para a responsabilidade do Ministro Corregedor-geral Eleitoral, Geraldo Og Nicéas Marques Fernandes. Deste modo, ainda há muitos caminhos processuais a serem cumpridos antes do encerramento dessas ações.

Todavia, as decisões de antecipação de tutela proferidas na AIJE n. 0601771-28.2018.6.00.0000, Coligação "O Povo Feliz de Novo" (PT/PCdoB/PROS) x Jair Bolsonaro e outros, que é a ação mais ampla (com maior número de réus e fatos discutidos), e em alguns outros processos durante as eleições de 2018 são parâmetros que mostram o olhar que foi adotado pelo Poder Judiciário sobre a natureza que teriam os disparos de mensagens denunciados pela Folha de S. Paulo (MELLO, 2018).

Logo na primeira decisão proferida, na AIJE n. 060177128.2018.6.00.0000, o Desembargador Relator do Caso, Jorge Mussi, determinou que as empresas fossem excluídas da ação, sustentando-se no argumento de que a interpretação do Tribunal Eleitoral sobre a Lei Complementar no 64/90 (que trata dos casos de inelegibilidade) (BRASIL, 1990) se dá no sentido de que as pessoas jurídicas não podem sofrer as penalidades típicas da legislação eleitoral. Deste modo, Quick Mobile Desenvolvimento e Serviços Ltda, Yacows Desenvolvimento de Sotware Ltda, Croc Services Soluções de Informática Ltda, SMS Market Soluções Inteligentes Ltda e Whatsapp Inc. (Facebook Serviços Online do Brasil LTDA.) foram excluídos do rito processual.

Todavia, é interessante destacar que alguns argumentos apresentados pelos seus proprietários nas contestações mostram o justo contrário, apontando a existência de um trabalho organizado por empresas e contratado para prestar o serviço de disparo em massa de mensagens. Trata-se literalmente do cerne teórico da Economia Política da Comunicação, a saber: o trabalho produtor de audiência. Trata-se aqui de trabalho como serviço prestado por funcionários e organizado pelas 


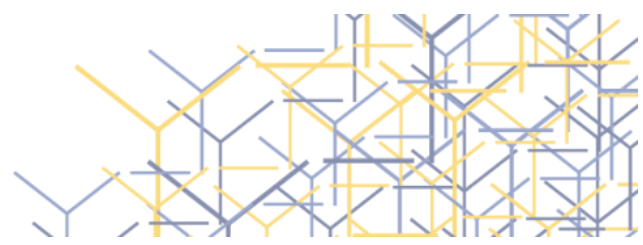

empresas que teriam sido contratadas durante as eleições para efetuar o disparo massivo de mensagens. Alguns trechos das defesas apresentadas pelos sócios da Yacows Desenvolvimento de Sotware Ltda e da SMS Market Soluções Inteligentes Ltda, respectivamente, demonstram isso:

A empresa Yacows possui mais de quatro mil clientes cadastrados, que se utilizam de sua plataforma digital para o envio de inúmeras mensagens todos os dias, com variados conteúdos e para diversos destinatários, por meio de WhatsApp e SMS, sendo assim humanamente impossível controlar ou fiscalizar o conteúdo das referidas mensagens. Mesmo porque não há exigência legal de que as empresas controlem o conteúdo de mensagens enviadas por particulares, ato que poderia até ser considerado de censura indevida - ora, ninguém é obrigado a fazer o que não está previsto em lei.

E não obstante possuir o cadastro de seus inúmeros usuários, que enviam mensagens livremente após a compra de créditos on line, a Yacows não tem condições de checar se o cadastro realizado via internet é verdadeiro ou se o cliente se utiliza de dados falsos para a utilização do sistema, o mesmo acontecendo com o conteúdo que cada uma das mensagens enviadas, sendo do usuário a responsabilidade pelo cadastro e pelo conteúdo das suas mensagens. Se eventualmente algum usuário realizou disparos que ferem as leis eleitorais, a responsabilidade é exclusivamente dele, devendo aludido usuário responder por seus atos, e não a Yacows ou seus sócios que apenas disponibilizam a ferramenta digital de envios de mensagens pela internet.

A Yacows não realizou nenhum disparo por conta própria para benefício de nenhum candidato, a plataforma foi utilizada por empresas e pessoas físicas que se cadastraram no serviço, compraram créditos e foram habilitadas a usar a ferramenta tecnológica digital de entrega de mensagens, apenas isso. Nada mais. (BRASIL, 2018a, grifo nosso).

$\mathrm{Na}$ própria defesa apresentada são dados os detalhes de funcionamento que apontam a existência de trabalho organizado.

Por sua vez, a SMS Market confirmou que a empresa teve sua conta de Whatsapp bloqueada, pelas políticas de segurança do próprio aplicativo, face o grande volume de mensagens que teriam sido enviadas - negando, genericamente, agir fora da lei (BRASIL, 2018a). 


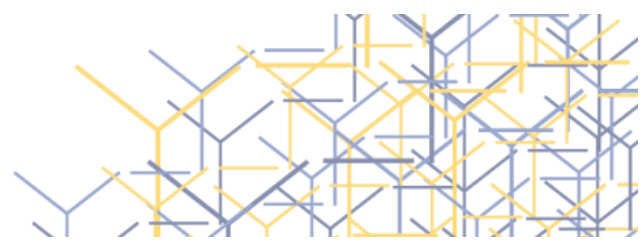

Diversas outras ações foram protocoladas - por ambas as coligações majoritárias de 2018 - pedindo, de alguma forma, a intervenção do Poder Judiciário em atos de campanha praticados através do Facebook e do WhatsApp. Dentre os 20 processos encontrados através de busca junto ao site do TSE consoante critérios acima demonstrados, nos registrados sob os no 0601764-36.2018.6.00.0000, 0601766-06.2018.6.00.0000, 0601758-29.2018.6.00.0000, 0601765-21.2018.6.00.0000 e 060176521.2018.6.00.0000, houve o questionamento das identidades das pessoas físicas que veicularam material de campanha em favor do então candidato Jair Messias Bolsonaro, postulando sua identificação - que é obrigatória, diante do que estabelece a Resolução no 23.551/2017 do TSE.

Contudo, a posição da Corte se deu, nos processos acima mencionados, no sentido de que não haveria anonimato suficiente para a concessão de alguma medida urgente de quebra de sigilo se o indivíduo, de alguma forma, se mostrasse como possível de ser identificado.

Na Representação Eleitoral de no 0601765-21.2018.6.00.0000, o TSE se posicionou na decisão liminar não reconhecendo nem o anonimato e nem o uso de perfis falsos. A Corte também entendeu que as manifestações trazidas como criminosas eram na verdade opiniões espontâneas do eleitorado, que não podem ser penalizadas por serem permitidas por lei:

[...] não constatados o falseamento de identidade ou o anonimato e vedada a adoção de interpretação extensiva para incidência de multa, é inviável o deferimento do pedido de aplicação de sanção aos responsáveis pela divulgação do conteúdo alegado inverídico e ofensivo. [...] Ademais, a Res.TSE no 23.551/2017, em seu $\S 6^{\circ}$ do art. 23, afasta a responsabilidade das pessoas naturais que, espontaneamente, se manifestarem na Internet em matéria político-eleitoral - sob a forma de elogio ou crítica a candidato ou partido político - por meio de blogs, redes sociais, sítios de mensagens instantâneas e aplicações de Internet assemelhadas cujo conteúdo seja gerado ou editado. (BRASIL, 2018d). 
Outro argumento recorrente utilizado pelo TSE nas ações estudadas está no artigo 33 da Resolução n. 23.551/2017 da Corte, que postula que "A atuação da Justiça Eleitoral em relação a conteúdos divulgados na internet deve ser realizada com a menor interferência possível no debate democrático" (TSE, 2017). A partir desse fundamento, o Tribunal posicionou-se no sentido de que os atos reputados como propagandas eleitorais eram, em verdade, meras manifestações de opinião que refletiam o embate democrático, motivo pelo qual prescindiriam de intervenção pelo Poder Judiciário.

Coincidentemente, poucos dias antes da publicação da matéria da Folha de S. Paulo, o presidenciável Jair Messias Bolsonaro ajuizou a Representação Eleitoral registrada sob o n. 0601686-42.2018.6.00.0000 contra WhatsApp Inc. - Law Enforcement \& Safety Manager, postulando a identificação de usuários que teriam veiculado vídeos supostamente falaciosos e ofensivos em seu desfavor.

O Relator Ministro Carlos Horbach decidiu de forma oposta, não apenas reconhecendo indícios de prática ilícita como também determinando ao Whatsapp que, em $48 \mathrm{~h}$, identificasse os perfis dos usuários que teriam realizado os disparos apontados pelo presidenciável no pedido inicial do processo:

Determino, também, a WhatsApp Inc. - Law Enforcement \& Safety Manager que (a) efetue, no prazo de $24 \mathrm{~h}$, o bloqueio do encaminhamento sucessivo da URL https://mmgfna.whatsapp.net/d/f/AkhILOVq9DnbxiZhu3Ieu2 tS9NTg-My7hw4SZQn4qAPW.enc

no aplicativo WhatsApp; (b) proceda, no prazo de $48 \mathrm{~h}$, à identificação do algoritmo de Hash do referido arquivo; e (c) realize, igualmente no prazo de $48 \mathrm{~h}$, o rastreamento do mais remoto upload do arquivo e identificação do usuário responsável. (BRASIL, 2018e).

Em 2 de maio de 2019, a Prestação de Contas da Coligação majoritária "Brasil acima de tudo, Deus acima de todos" foi aprovada. As 


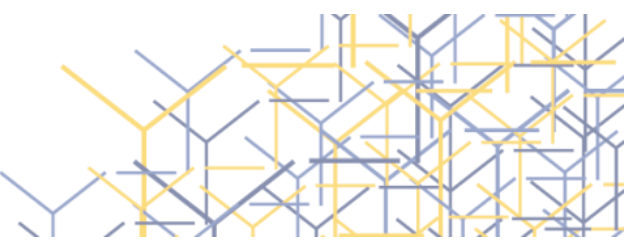

únicas ressalvas que o TSE impôs foram o pagamento de duas multas, no valor de $\mathrm{R} \$ 5.200,00$ e $\mathrm{R} \$ 3.075,00$ pelo recebimento de doações de fontes vedadas e não identificadas, respectivamente.

Nenhuma dessas multas tem vinculação com a contratação de disparo massivo de mensagens. O Ministro Relator da Prestação de Contas, Luis Roberto Barroso, entendeu que "o exame técnico realizado nos processos de prestação de contas não impede que outros órgãos - tais como o Ministério Público Eleitoral - investiguem fatos que possam configurar ilícitos penais, civis ou administrativos" (BRASIL, 2018c), justificando, logo em seguida, que o uso indevido de meios de comunicação não são questões próprias do processo de prestação de contas.

Dentro do exame jurídico da situação apontada pela Folha de S. Paulo, por mais que ainda não haja conclusão dos processos judiciais, a posição que o TSE adotou durante as eleições pode ter sido determinante para o resultado do pleito - tendo em vista que uma eventual condenação poderia resultar na inelegibilidade da coligação "Brasil acima de tudo, Deus acima de todos" (PSL/PRTB).

Mesmo que haja uma radical mudança na posição ostentada pela Corte Eleitoral, até a conclusão deste trabalho já havia transcorrido o primeiro quarto do governo do candidato escolhido. Considerando-se ainda a possibilidade de recursos e a própria mora da tramitação processual, a viabilidade de uma decisão contrária ao presidente eleito tem eficácia questionável.

Enfim, a novidade do aparato legal próprio ao impulsionamento de mensagens em plataformas de redes sociais transparece uma tentativa escorregadia de lidar com uma conjuntura avassaladora e desconhecida. As empresas envolvidas demonstram saber dos limites legais com que lidam, mas ignoram as ações desempenhadas pelas campanhas contratantes com os serviços por elas prestados. As campanhas persistem em afirmar que nada sabem, mas com afirmativas que mal disfarçam a consciência geral de que os marcos regulatórios não dão conta do que as plataformas digitais 


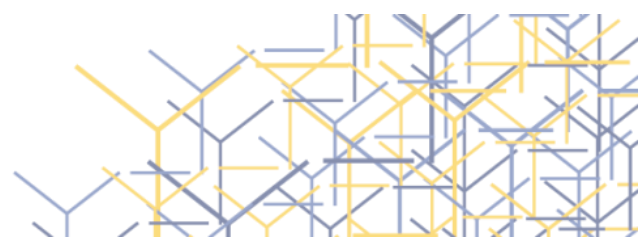

podem desempenhar. Propomos, contudo, que uma interpretação dessas questões que se fundamente em debates próprios às Teorias da Comunicação pode elucidar pontos obscuros e apontar lacunas na legislação pertinente e nas decisões judiciais.

Visando esse caminho, façamos uma interpretação dos dados obtidos na análise acima sob as lentes de alguns conceitos tecidos pela (Crítica Dialética) da Economia Política da Comunicação (EPC). Por (Crítica Dialética) da EPC nos referimos, sobretudo, ao âmbito teórico desenvolvido a partir da obra de César Bolaño (2000). Trata-se de estabelecer um marco teórico geral para a Comunicação, principalmente interessado em seus fundamentos econômicos, sintetizando (e, em certo sentido, superando) os achados teóricos parciais alcançados até então. Bolaño define da seguinte forma sua proposta teórica:

O marco teórico que propus é geral, em primeiro lugar, porque incorpora criticamente, num todo coerente, as teorias parciais que historicamente se dedicaram a cada uma das três condições de funcionalidade: a função publicidade (Baran e Sweezy, Dallas Smythe), que explicita o papel da indústria cultural no processo de acumulação do grande capital monopolista em concorrência; a função propaganda (teorias dos aparelhos ideológicos de Estado ou do imperialismo ou dependência cultural), que esclarece seu papel na reprodução ideológica do sistema; e a função programa (estudos culturais), que se refere às condições da recepção. Em segundo lugar, as contribuições da escola francesa são incorporadas, também criticamente, no momento da análise das especificidades do sistema de mediação que é a indústria cultural, referentes aos processos de trabalho e de valorização (BOLAÑO, 2000, p. 46).

Para isso, a (Crítica Dialética da) EPC, em César Bolaño (2000), reconhece a comunicação como uma forma social. Ou seja, significa dizer que a comunicação corresponde, antes de tudo, a uma forma de manifestação adequada às determinações do capital. Ela dá conta das interações entre sujeitos próprias ao capitalismo em seus momentos específicos, aqui entendidos em princípio de um ponto de vista lógico 
(portanto, absolutamente abstrato). Assim, para expor tal forma, Bolaño (2000) recorreu a uma observação das características próprias à troca de informações necessária em dois momentos decisivos da apresentação marxiana do capital, a saber: a circulação simples de mercadorias e o terreno oculto da produção.

No que diz respeito ao momento da circulação simples de mercadorias, trata-se de observar como portadores de mercadorias, formalmente livres, se encontram e interagem por meio do intercâmbio de informações visando à troca de mercadorias. Essas informações são diretas e objetivas e, sem mediações, caracterizam o "processo cooperativo de interpretação" relativo aos momentos da metamorfose das mercadorias que se apresentam nas transações praticadas pelos possuidores de mercadorias: a venda (troca de mercadoria por dinheiro) e a compra (troca de dinheiro por mercadoria). No terreno oculto da produção, por sua vez, a igualdade formal desaparece e nos deparamos com personagens mais específicos: o capitalista e seu trabalhador. A informação trocada entre pessoas formalmente livres e iguais se transmuta numa informação hierarquizada e burocratizada, ainda direta, objetiva e não mediada, mas como uma informação de classe.

Cumpre lembrar que a passagem histórica da cooperação simples à grande indústria avaliada por Marx (2017), em O Capital, passagem que leva justamente ao longo processo que consolida o terreno oculto da produção como o lócus da informação de classe, está baseada na apropriação de conhecimentos desenvolvidos primeiro pelos próprios artesãos e, com o tempo, pelos trabalhadores das fábricas. Bolaño (2000) descreve esse processo como a acumulação primitiva de conhecimento.

Daí surge uma bifurcação da informação característica do terreno oculto da produção: de um lado, a informação de classe, própria do processo produtivo de mercadorias, mas que não é ela mesma mercadoria; de outro, a informação agregada como insumo no processo produtivo e que detém a possibilidade de ser uma mercadoria-informação, atuando no 
âmbito da concorrência capitalista. O desenvolvimento dos grandes sistemas de comunicação capazes de acumular e controlar a informação mantém esses dois âmbitos da informação em uma interação contraditória.

A assim chamada massificação responde ao duplo processo de crescimento exponencial do uso intensivo de força humana de trabalho e consumo massificado de mercadorias em expansão. Nesse âmbito, os grandes sistemas de comunicação, fundamentados no monopólio de um aparelho de Estado ou de um setor específico do capital, garantem a igualdade aparente de liberdade de acesso à informação, encobrindo o fundamento da desigualdade de classe da informação no processo de trabalho. Em termos lógicos, trata-se de apontar aí uma contradição própria à forma-comunicação: de um lado, a forma diretamente ideológica da informação, chamada de propaganda; de outro, a forma dedicada ao fluxo de mercadorias (e ideologicamente comprometida em constituir um modo de vida capitalista), chamada de publicidade. Longe de ser uma disfuncionalidade, a contradição é seu fundamento formal. Portanto, as condições de possibilidade e a necessidade lógica dos sistemas de comunicação de massa, bem como os aparatos estatais que os viabilizem, estão derivadas dessa contradição formal.

Historicamente, a autonomização da mercadoria-informação externalizou essa contradição, surgindo as funções de publicidade e propaganda, capazes de lidar concretamente com as contradições formais da comunicação, bem como as instâncias específicas a darem conta delas, efetivando-se naquilo que conhecemos por Indústria Cultural, as condicionantes oligopolistas que a fundamentam economicamente e os marcos regulatórios que garantem sua existência. Seguindo Bolaño (2000), podemos afirmar que as contradições formais próprias à comunicação se desdobram no duplo caráter do trabalho particular à Indústria Cultural e as duas mercadorias por ele produzido. Tal trabalho produz os programas que abastecem a Indústria Cultural que, quando consumidos pelo público, se expressam em números abstratos de pessoas tornadas audiência - que são 
aquilo que satisfaz as necessidades dos anunciantes, ao comprarem espaço para seus anúncios. Assim se constitui a contradição da mercadoriaaudiência.

Para Bolaño (2000, p. 222), o trabalho concreto da comunicação tem duplo valor, ao produzir o objeto comunicativo e a audiência. A audiência como mercadoria foi um achado teórico do pensador canadense Dallas Smythe (1977). Para Smythe, tratava-se de vencer o que ele compreendia como idealismo do pensamento crítico até aquele momento, que não se interessava pelo papel econômico cumprido pela comunicação na dinâmica do capitalismo monopolista. Nesse sentido, Smythe resolveu buscar uma abordagem materialista cuja pergunta de pesquisa era: qual a mercadoria que a indústria da comunicação produz? Sua resposta estava na audiência.

Menos interessado nas concepções críticas da publicidade, que reconheciam na comunicação apenas uma dinâmica de manipulação, Smythe entendia que a comunicação operava o papel de estabelecer a solução para o problema da demanda e da concorrência em situação de grandes monopólios. Assim, a audiência ela mesma operava um papel na produção de valor da mercadoria que seria vendida no mercado de anúncios publicitários.

A rigor, trata-se de dotar a audiência de uma condição de participação ativa e espontânea em sua produção como mercadoria, mais especificamente entendida como trabalho da audiência. Assim, suas ações não são resultantes das relações de comunicação estabelecidas pelas corporações, significando, para Smythe, trabalho da audiência que produz seu valor.

Criticando o argumento teórico de Smythe (1977), Bolaño (2000, p. 224) reafirma o trabalho concreto da comunicação exercido pelos profissionais das empresas de comunicação. Nesse sentido, o público é tornado audiência pelo trabalho comunicacional. A relação do público, reificado em audiência, com a Indústria Cultural é uma relação de comunicação, não de trabalho. Capitais individuais (empresas), de um lado, 
e Estado (agentes políticos), de outro, visam comunicar-se com o público, por meio da Indústria Cultural, que vende seu serviço produzindo audiência por meio do trabalho de seus profissionais e oferecendo-a como mercadoria. Empresas e Estado compram essa mercadoria visando realizar seus interesses, respectivamente, na função publicidade e na função propaganda.

Mas, se não há trabalho da audiência em se produzir, como o trabalho de comunicação consegue tornar o público em mercadoria-audiência? A capacidade que a Indústria Cultural tem de atrair a atenção do público para cumprir as funções propaganda e publicidade é o que Bolaño chama de "função programa". Essa função "[...] vem a ser cumprida pela Indústria Cultural a partir do momento em que formas mais orgânicas, ligadas à cultura popular, de criação de significados, são deslocadas e apropriadas por ela" (BOLAÑO, 2000, p. 241). Assim, a Função Programa é resultado das outras funções exercidas pela Indústria Cultural. As massas são expostas a esta função emocionalmente quando se identificam com seus próprios símbolos culturais. A análise que pode ser feita a respeito da função programa mostra que a audiência não é o único benefício mercadológico para o capital, mas que através dela o domínio político sobre as massas é assegurado. Não há espontaneidade nesse processo.

Pode-se concluir que o sujeito (o trabalhador) torna-se mais do que nunca com a Indústria Cultural, objeto: não é apenas a sua força de trabalho que se torna mercadoria, mas a sua própria consciência e seus desejos são apropriados para facilitar a acumulação do capital (BOLAÑO, 2000 p. 227).

Ao avaliarmos as disputas eleitorais, podemos afirmar que elas funcionaram em meio às contradições particulares da Indústria Cultural como única instância específica que dá conta das duas funções próprias à contradição formal da comunicação. As questões políticas ganham vida por 


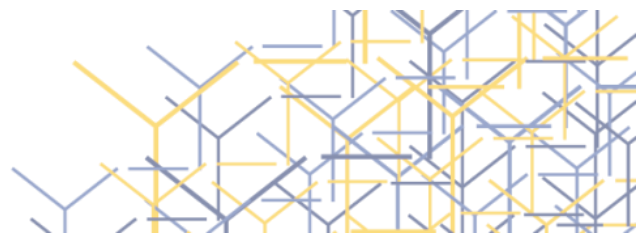

meio da mercadoria própria à Indústria Cultural e seu duplo caráter, o que gera a dinâmica que conhecemos das campanhas eleitorais.

Ao longo do tempo, as organizações político-partidárias se pautaram cada vez mais em torno das dinâmicas próprias às campanhas eleitorais e o desdobramento da função propaganda por meio do duplo caráter da mercadoria própria à Indústria Cultural, num crescimento da participação do pensamento ligado ao marketing. Os aparatos legais que dizem respeito a tais processos visam regular as contradições próprias a este duplo caráter - ou seja, limitam e viabilizam suas condições, visando satisfazer às dinâmicas cíclicas do capital.

Assim, transpondo o fundamento conceitual de Bolaño para o objeto estudado, devemos reconhecer que as principais considerações sobre as acusações em torno dos disparos de mensagens em massa pelo WhatsApp estão no uso indevido dos serviços de empresas especializadas (a partir da construção de lista de destinatários e envio massivo de mensagens) e no pagamento do serviço por empresas apoiadoras do candidato, ou seja, na produção de audiência e sua compra.

Por sua vez, a Justiça Eleitoral, até o presente momento, entende que deve se concentrar nas ações dos candidatos e chapas, que são os sujeitos que podem ser penalizados. Com isso, ao ignorar o pagamento ilegal de propaganda por Pessoas Jurídicas, não dá atenção para o trabalho desenvolvido pelas empresas contratadas. Podemos entender que o tipo de avaliação proposto pela Justiça Eleitoral, ao ressaltar o papel dos eleitores na disseminação de notícias, está próximo do argumento de Smythe, que lega à audiência o papel de produtora de si mesma.

Por outro lado, entendemos que Bolaño (2000) apresenta um quadro mais complexo e mais robusto para a compreensão do problema. A partir dele, podemos afirmar que, sem a devida avaliação do todo comunicativo em jogo, levado em conta o candidato como comprador de audiência produzida pelo trabalho concentrado pelas empresas de comunicação, a Justiça Eleitoral se vê diante de uma lacuna teórica grave e que interfere 
sobremaneira na condução dos processos eleitorais em particular como na democracia como um todo.

Quando as campanhas eleitorais estavam restritas aos meios massivos ditos tradicionais, a Legislação Eleitoral visou dotar as eleições do máximo de isonomia econômica (com a Propaganda Eleitoral gratuita), portanto, coibindo ganhos políticos com mais condições de compra de mercadoria audiência visando maior eficácia de sua propaganda. Com a ascensão das mídias digitais e o crescimento das campanhas nessa modalidade, a Justiça Eleitoral parece não conseguir manter seus esforços isonômicos, impossíveis de serem alcançados apenas com o olhar proporcionado pelo direito.

\section{Considerações finais}

Até a conclusão deste estudo, não foi possível estabelecer qual é a posição definitiva do TSE a respeito dos disparos massivos de mensagens pelas redes sociais supostamente contratados à época das eleições presidenciais de 2018. Isso porque, como dantes apontado, a maioria dos processos ainda não foi concluído - em especial, as três AIJEs, que postulam especificamente a realização de atos investigatórios, continuam a tramitar, com a reabertura da fase de produção de provas diante da confissão do WhatsApp.

O fato é que, no momento do pleito eleitoral, a posição que a Justiça decidiu adotar foi uníssona, em diversos julgados, no sentido de esvaziar a possibilidade da existência de uma circulação organizada de audiência (enquanto mercadoria), rotulando as atividades denunciadas pela Folha de S. Paulo (MELLO, 2018) como mera manifestação espontânea do eleitorado, colocando toda a problemática apresentada à margem da competência de sua atuação. Além dos fatores políticos que certamente influenciam essa tomada de posição, buscamos demonstrar nesse estudo que também existe 
uma lacuna legal, tendo em vista que a letra da lei tampouco permite uma análise mais crítica da problemática apresentada.

Apesar dos estudos realizados também a respeito dos temas democracia, comunicação, desinformação e fake news, mapeados e apontados no início deste estudo, os estudos da (Crítica Dialética da) Economia Política da Comunicação têm sinalizado a existência de novas saídas para o entendimento do objeto recortado neste artigo. Através da sobreposição dos conceitos tecidos por Bolaño, é possível descaracterizar a circulação massiva de mensagens pelo WhatsApp como movimento espontâneo, dando sentido aos diversos indícios apresentados de que existe uma atividade econômica organizada.

A importância que a audiência possui é uma das consequências da sua posição enquanto mercadoria - status esse de que passa a usufruir com as novas configurações da forma social comunicação na Indústria Cultural (BOLAÑO, 2000) - o que mitiga, inclusive, o valor do conteúdo veiculado, possibilitando a disseminação das chamadas fake news. Tem-se, na situação denunciada por Mello (2018), à luz dos conceitos teóricos apresentados, a produção e a compra da audiência enquanto mercadoria, viabilizada através da atuação ilegal de Pessoas Jurídicas especializadas na prestação desse serviço.

São estudos relativamente recentes, na perspectiva acadêmica, mas que têm demonstrado conclusões mais apuradas a respeito da relação entre comunicação e democracia, cujo aprimoramento, neste momento de crise cíclico de reformulação do capital, se mostra como contribuição decisiva e fundamental. 


\section{Referências}

BOLAÑO, César Ricardo Siqueira. Indústria cultural: informação e capitalismo. São Paulo: Pólis/Hucitec, 2000.

BRASIL. Lei complementar nº 64, de 18 de maio de 1990. Diário Oficial da União, Brasília, 21 mai.1990. Disponível em:

http://www.planalto.gov.br/ccivil 03/LEIS/LCP/Lcp64.htm. Acesso em: 19 set. 2019.

BRASIL. Lei no 13.448, de 06 de outubro de 2017. Diário Oficial da União, Brasília, 06 out. 2017. Disponível em:

http://www.planalto.gov.br/ccivil 03/ Ato2015-

2018/2017/Lei/L13488.htm. Acesso em: 19 set. 2019.

BRASIL. Lei no 4.737, de 15 de julho de 1965. Diário Oficial da União, Brasília, 19 dez.1965. Disponível em:

http://www.planalto.gov.br/ccivil 03/leis/14737.htm. Acesso em: 19 set. 2019.

BRASIL. Lei no 9.504, de 30 de setembro de 1997. Diário Oficial da União, Brasília, 01 out.1997. Disponível em:

http://www.planalto.gov.br/ccivil 03/leis/L9504.htm. Acesso em: 19 set. 2019.

BRASIL. Ação de Investigação Judicial Eleitoral no 0601771 28.2018.6.00.0000. Tribunal Superior Eleitoral, Brasília, autuado em 18 out. 2018a. Disponível em: https://pje.tse.jus.br:8443/pjeweb/ConsultaPublica/listView.seam. Acesso em 15.mar.2020. Acesso em: 19 mar. 2020.

BRASIL. Ação de Investigação Judicial Eleitoral no 0601782-

57.2018.6.00.0000. Tribunal Superior Eleitoral, Brasília, autuado em 20 out. 2018b. Disponível em: https://pje.tse.jus.br:8443/pjeweb/Processo/ConsultaProcesso/listView.seam. Acesso em: 19 mar. 2020.

BRASIL. Prestação de Contas no 0601225-70.2018.6.00.0000. Tribunal Superior Eleitoral, Brasília, autuado em 13 set. 2018c. Disponível em: https://pje.tse.jus.br:8443/pje-web/ConsultaPublica/listView.seam. Acesso em: 15 mar. 2020.

BRASIL. Representação Eleitoral no 0601765-21.2018.6.00.0000.

Tribunal Superior Eleitoral, Brasília, autuado em 17 out. 2018d.

Disponível em: https://pje.tse.jus.br:8443/pjeweb/ConsultaPublica/listView.seam. Acesso em: 15 mar. 2020. 
BRASIL. Representação Eleitoral no 0601686-42.2018.6.00.0000. Tribunal Superior Eleitoral, Brasília, autuado em 12 out. $2018 \mathrm{e}$. Disponível em: https://pje.tse.jus.br:8443/pjeweb/ConsultaPublica/listView.seam. Acesso em: 15 mar. 2020.

FABRINI, Fábio. Não temos solução pronta para Fake News, diz Rosa Weber. Folha de S. Paulo, São Paulo, 21 out. 2018. Disponível em: https://www1.folha.uol.com.br/poder/2018/10/nao-temos-solucaopronta-para-fake-news-diz-rosa-weber.shtml. Acesso em: 22 mar. 2020.

MARX, Karl. O Capital. São Paulo: Edipro, 2017.

MELLO, Patrícia Campos. Empresários bancam campanha contra o PT pelo WhatsApp. Folha de S. Paulo, São Paulo, 18 out. 2018. Disponível em: https://www1.folha.uol.com.br/poder/2018/10/empresarios-bancamcampanha-contra-o-pt-pelo-whatsapp.shtml. Acesso em: 19 mar. 2020.

SMYTHE, Dallas. Communications: Blindspot of Western Marxism.

Canadian Journal of Political and Social Theory, Winnipeg, v. 1, n. 3, p. 1-27, out. 1977.

TSE. Termo de compromisso. Diário de Justiça Eleitoral, Brasília, 05 jun. 2018a. Disponível em:

http://www.justicaeleitoral.jus.br/arquivos/termo-de-compromisso-compartidos-politicos-contra-noticias-falsas-nas-eleicoes-

2018/rybena pdf?file=http://www.justicaeleitoral.jus.br/arquivos/termode-compromisso-com-partidos-politicos-contra-noticias-falsas-naseleicoes-2018/at download/file. Acesso em: 22 mar. 2020.

TSE. Resolução no 23.551, de 18 de dezembro de 2017. Diário de Justiça Eleitoral, Brasília, 05 fev. 2018b, p. 248-273. Disponível em: http://www.tse.jus.br/legislacao-tse/res/2017/RES235512017.html. Acesso em: 19 set. 2019. 